\title{
Reliability of DNA-based sex tests
}

7 he sexing of human DNA samples is 1 used in applications such as forensic and archaeological work ${ }^{1,2}$. In a commonly used test ${ }^{1}$, fragments that differ in size from the amelogenin (AMEL) gene loci on the $\mathrm{X}$ and $\mathrm{Y}$ chromosomes are amplified by the polymerase chain reaction (PCK; ref. 3). The presence of the

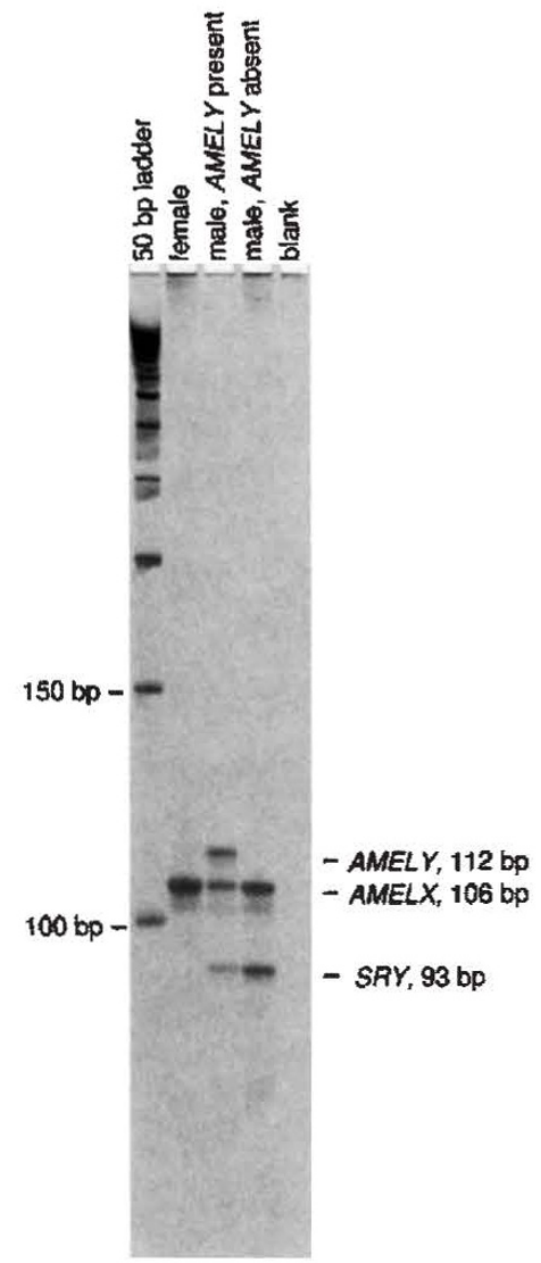

Fig. 1 Co-amplification of amelogenin and SRY Single-tube PCR reactions were carried out with the Amel-A and Amel- $B$ primers ${ }^{1}$ and additional primers from the SRY region: F11 5'-ATAAGTATCGACCTCGTCGGAA-3' and R7 5'-GCACTTCGCTGCA GAGTACCGA-3'. The volume was 12.5 ut and contained $1.5 \mathrm{mM} \mathrm{MgCl}, 200 \mu \mathrm{M}$ dNTPs, $1 \mu \mathrm{M}$ of each primer, $1 \cup$ Taq DNA polymerase (BioTaq from Bioline or AmpliTaq Gold from Perkin Elmer), with the buffer provided by the supplier, and about 20 ng of human genomic DNA. An initial denaturation at $94^{\circ} \mathrm{C}$ for $3 \mathrm{~min}$ for BioTaq or $10 \mathrm{~min}$ for AmpliTaq Gold was followed by 30 cycles of $94^{\circ} \mathrm{C}$ for $20 \mathrm{~s}$, $60{ }^{\circ} \mathrm{C}$ for $20 \mathrm{~s}$ and $72{ }^{\circ} \mathrm{C}$ for $45 \mathrm{~s}$. Products were run on a 1 -mm-thick, 20 -cm-long $8 \%$ polyacrylamide gel in $1 \times$ TBE buffer at a constant current of $40 \mathrm{~mA}$ for $2 \mathrm{~h}$ and silver stained?
$\mathrm{X}$-derived fragment demon- $a$ strates successful amplification of human DNA; on its own, it is taken to indicate a female sample, but when the Y-derived fragment is also present, the sample is considered to be male. We now report that this assay incorrectly types some males as females because they lack the Y copy of the amelogenin gene as a result of a deletion polymorphism.

A total of 350 unrelated normal male DNA samples from around the world were tested by hybridization or PCR for the presence of 37 Y-chromosomal loci. Details of the populations screened are available upon request. Two individuals were found to lack several loci from the short arm, including 50f2/A (DYS7/A), 50f2/B (DYS7/B), 92R7/A and LLY22g/A,B,C,F, detected by hybridization ${ }^{4}$, and $A M E L Y$, detected by PCR (Fig. 1). Alternative primers derived from the published $A M E L$ sequences ${ }^{5}$ also produced only the $\mathrm{X}$-derived product, suggesting that the absence of the AMELY product was due to

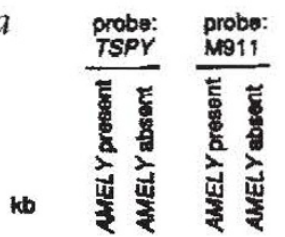
$b$
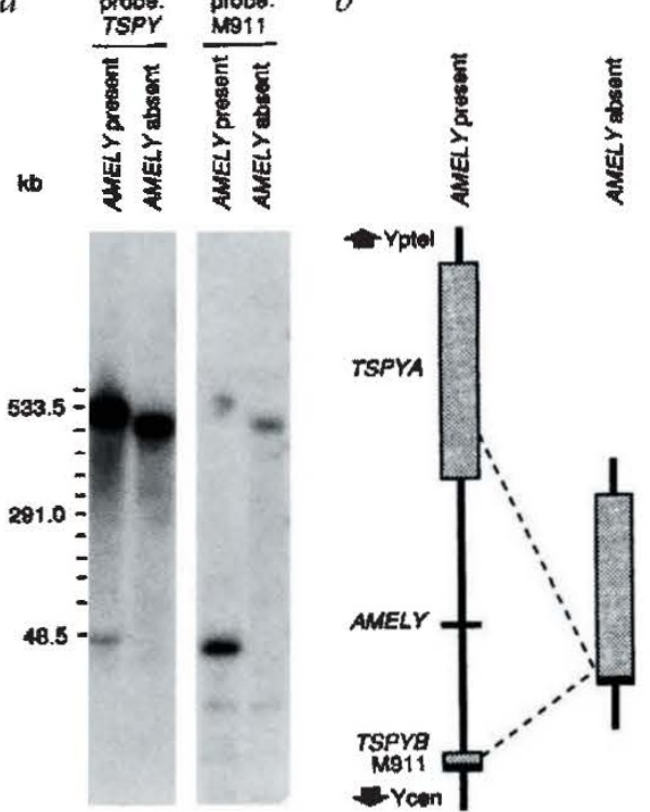

Fig. 2 Structure of the deletion polymorphism. a, DNA from an individual with the common $Y$ structure (AMELY present) or the rare $Y$ structure (AMELY absent) was digested with $X b a l$, fractionated by 'waltzer' pulsed-field gel electrophoresis (1.5\% agarose, $0.5 \times$ TAE buffer, $150 \mathrm{~V}, 50$-s pulse time, 24-h run) and probed with TSPY or M911. b. Schematic representation of the TSPY. AMELY and M911 loci (not to scale). The TSPY Xbal fragments are represented by grey boxes and M911 by a small black box. AMELY lies between the TSPYA and TSPYB arrays. The dotted lines show the suggested location of the deletion.

deletion of the Y-encoded gene rather than a polymorphism at one of the priming sites. SRY, the male sexdetermining gene ${ }^{6}$, was present as expected from the phenotype. Further analysis (Fig. 2) showed that the TSPYA (Y-190 major) array was present, but TSPYB (Y190 minor) was absent from males with the deletion. M911, a low-copy sequence usually located at the proximal edge of the TSPYB array, was present but associated with TSPYA. We suggest that a homologous recombination event between TSPYA and TSPYB has deleted the intervening region that includes the AMELY gene (Fig, 2b).

The frequency of this deletion polymorphism in our sample was low $(0.6 \%)$. Nevertheless, such an error may be unacceptable in some situations, and the frequency may be higher in some populations: the two individuals with the deletion both came from Sri Lanka, where the frequency in our sample was $2 / 24$
$(8 \%)$. The frequency in past populations represented by archaeological specimens is unknown. When it is important that a DNA-based sex test make the correct prediction, as in some forensic work and prenatal diagnosis, we suggest that the SRY locus also be included (Fig. 1).

\section{Fabrício R. Santos, Arpita Pandya \& Chris Tyler-Smith}

CRC Chromosome Molecular Biology Group, Department of Biochemistry, University of Oxford, South Parks Road, Oxford OX1 3QU, UK. e-mail: chris@bioch.ox.ac.uk

\footnotetext{
1. Sullivan, K.M., Mannucci, A., Kimpton, C.P. \& Gill, P. Biotechniques 15, 636-641 (1993).

2. Faerman, M. et al. Nature 385, 212-213 (1997).

3. Saiki, R.K. et ai. Science 239, 487-491 (1988).

4. Tyler-5mith, C. et al. Nature Genet. 5, 368-375 (1993).

5. Nakahori, Y. et al. Genomics 9, 264-269 (1991\}.

6. Sinclair, A.H. et al. Nature 346, 240-244 (1990).

7. Santos, F.R., Bianchi, N.O. \& Pena, S.D.J. Genome
} Res. 6, 601-611 (1996). 